\title{
DRUG REPURPOSING FOR TREATMENT OF COVID-19 PATIENTS
}

\author{
MOHD YUSMAIDIE AZIZ ${ }^{1 *}$ AND HISHAM ATAN EDINUR ${ }^{2}$ \\ ${ }^{1}$ Integrative Medicine Cluster, Advanced Medical and Dental Institute, 13200 Universiti Sains Malaysia, Penang, Malaysia. \\ ${ }^{2}$ School of Health Sciences, Universiti Sains Malaysia, Health Campus, 16150 Kubang Kerian, Kelantan, Malaysia.
}

*Corresponding author: mohd.yusmaidie@usm.my

Submitted final draft: 21 August $2020 \quad$ Accepted: 6 September 2020

http://doi.org/10.46754/jssm.2021.08.002

\begin{abstract}
Coronavirus disease 2019 (COVID-19) caused by the novel severe acute respiratory syndrome coronavirus-2 (SARS-CoV-2) has claimed more than four million lives worldwide. Daily cases and death rates are on the rise and, unfortunately, the therapeutic vaccine or drug treatment is still nowhere to be found. Finding a cure for viruses is not easy, as vaccine and drug development may take many years of trial and error. There is, however, a way to speed up the process by repurposing the available drugs on the market. Considering that all physico-chemical properties, efficacy, and safety profiles of the drugs have been established, we believe that by repurposing drugs, it would provide a short cut in finding a cure for COVID-19. In the second opinion, we believe that a combination of drugs will also be beneficial in preventing a recurrence of infection. Thus, here we highlight several combinations of drugs that have potential to treat COVID-19.
\end{abstract}

Keywords: COVID-19, SARS-CoV-2, Kaletra, chloroquine, remdesivir.

Dear editor,

Adisease with pneumonia symptoms of unknown etiology was first reported in Wuhan, China, in December 2019 (Wu \& McGoogan, 2020). It was subsequently named coronavirus disease 2019 (COVID-19) after being determined as a novel zoonotic disease cause by the severe acute respiratory syndrome coronavirus-2 (SARSCoV-2). In just three to four months, the deadly SARS-CoV-2 has infected three million people, spreading widely and rapidly via human-tohuman transmissions in more than 210 countries. COVID-19 thus became a global health problem and was declared a pandemic the World Health Organisation (WHO) on $11^{\text {th }}$ March 2020 (Che Mat et al., 2020).

Many health institutions and hospitals are now facing a shortfall of beds, especially in their intensive care unit (ICU), putting the healthcare system of countries at breaking point in accommodating a growing number of COVID-19 cases. And we are yet to find a therapeutic regimen for these patients. The development of new drugs for SARS-CoV-2 infection may not be a good option due to its lengthy procedure, including the time needed for pre-clinical and clinical trials. Thus, the possible and feasible alternative for COVID-19 treatment is by repurposing existing drugs. Out of the thousands of drugs available in the market, some may be therapeutically effective in treating COVID-19 patients.

COVID-19 patients will normally develop clinical symptoms like fever, dry cough, fatigue, muscle aches, flu and sore throat at the onset of infection. These symptoms may deteriorate into respiratory problems, leading to pneumonia (lung infection). COVID-19 patients are usually treated based on symptoms, which may or may not completely kill or eliminate the viruses. Therefore, the possibility of SARS$\mathrm{CoV}-2$ recurrence in discharged patients or infecting those in close contact cannot be discounted (Chen et al., 2020). There are studies looking at the possibility of using drugs, such as antivirals, anti-inflammatory agents and antibiotics, to treat COVID-19 patients, and some of them are listed in Table 1. 


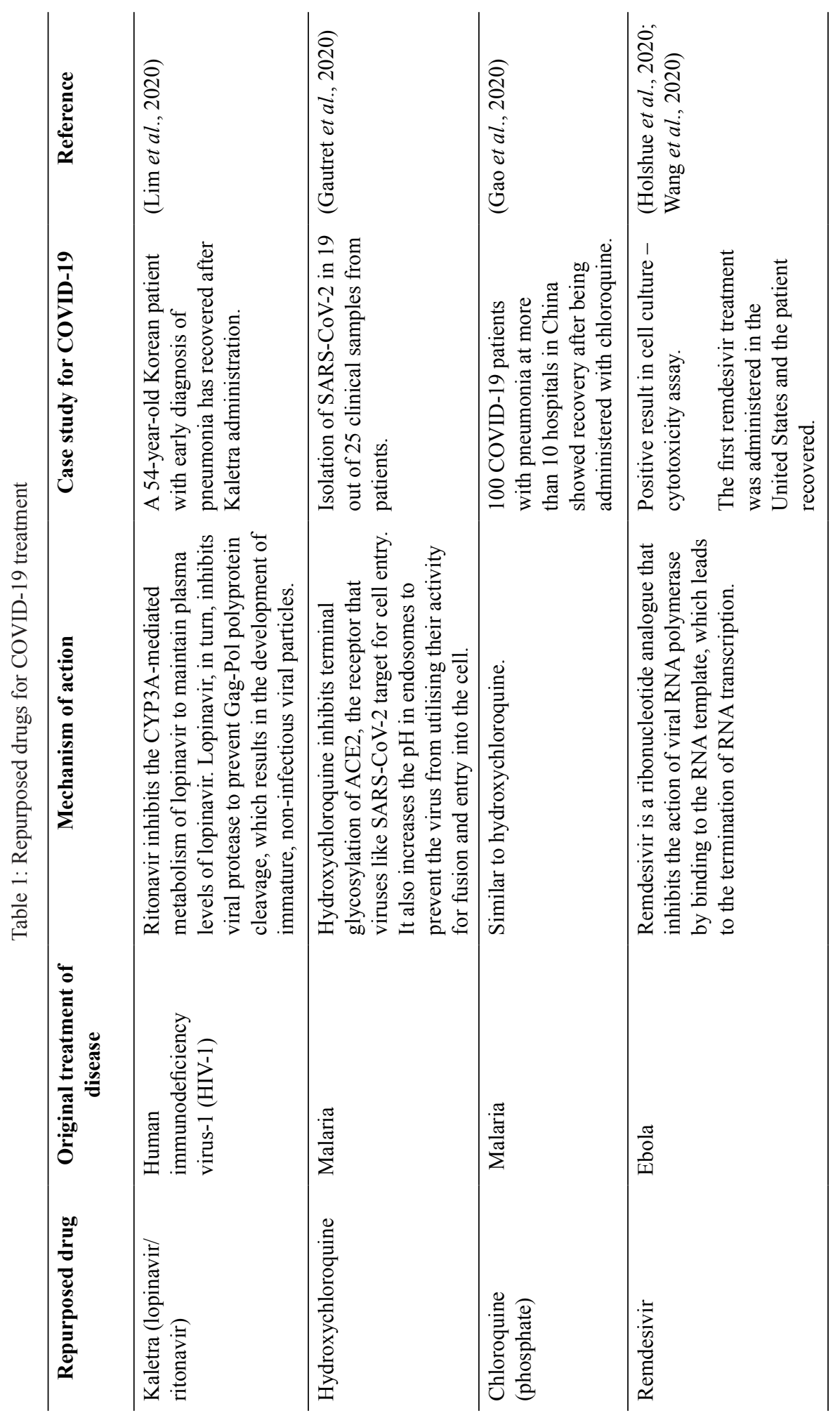




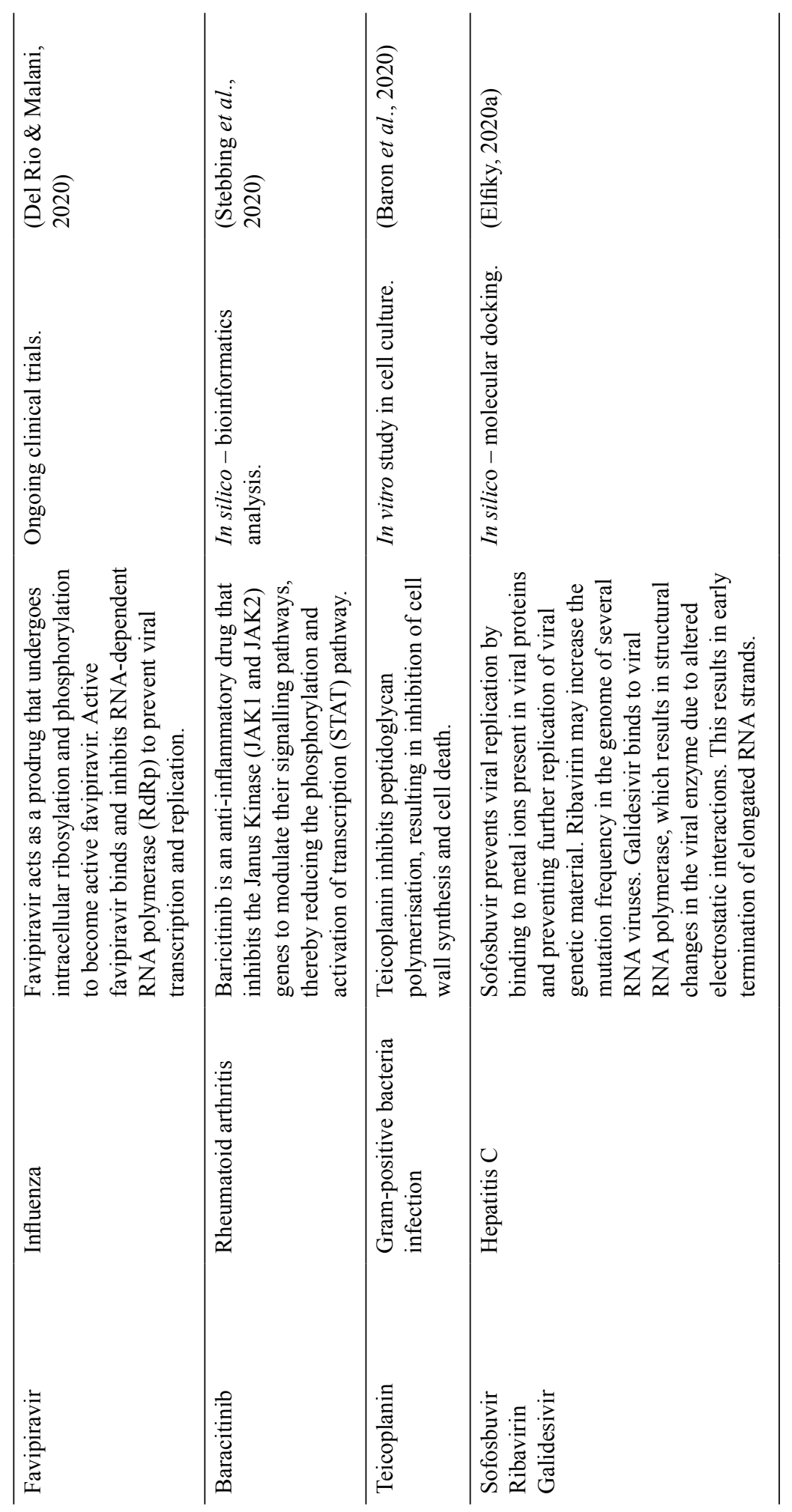

Journal of Sustainability Science and Management Volume 16 Number 6, August 2021: 4-9 
Among the drugs, Kaletra (a combination of two anti-HIV drugs lopinavir and ritonavir) seems to have the highest potential to treat COVID-19 infection. Kaletra is taken orally and recommended for high-risk COVID-19 pneumonia groups, particularly elderly patients or those with underlying diseases (Lim et al., 2020; Xu et al., 2020). Kaletra is originally developed to treat adults and children with HIV but is later found to be safe for all population groups (Puthanakit, 2010). Polytherapy using a combination of several drugs is a common medical procedure, especially for treatment of HIV, tuberculosis, and malaria, to avoid relapse and disease recurrence. With the half-life ranging from two to six hours, Kaletra may potentially be administrated in partner with other drugs that have a longer half-life to ensure a rapid and full elimination of SARS-CoV-2 in patients.

Theoretically, hydroxychloroquine or anti-malarial chloroquine may be a suitable partner to use in tandem with Kaletra because of its long half-life, which is around one to two months. The latter has also been shown to have apparent efficacy and acceptable safety against COVID-19 associated pneumonia cases in a clinical trial conducted in China (Gao et al., 2020). However, in vitro results have demonstrated that hydroxychloroquine is more potent than chloroquine when combined with the antibiotic azithromycin (Gautret et al., 2020; Yao et al., 2020).

Other potential repurposed drug for SARSCoV-2 is remdesivir, which is intended for Ebola patients. Remdesivir has been found to be highly effective in killing novel coronavirus in isolated cells, but its use for treating humans has yet to be approved. Nevertheless, two clinical trials for this drug are underway in China (Wang et al., 2020). A combination of remdesivir and anti-inflammatory agents such as baracitinib has been suggested as the pair is able to reduce viral infectivity and replication, besides attenuating lung inflammatory responses (Stebbing et al., 2020).

The antiviral favipiravir has also been tested to treat COVID-19. This drug was originally designed for influenza and is now at the clinical trial stage for COVID-19 treatment in China. Perhaps, it may be potentially used with a longer half-life anti-bacterial, such as Teicoplanin (half-life around three to four days), which showed positive results on COVID-19 cell culture experiments (Baron et al., 2020). Drug repurposing were also conducted using in silico approach to elucidate interactions between drugs and their effects on essential proteins of SARS-CoV-2. Results showed that sofosbuvir, ribavirin and galidesivir interacted with the coronavirus, but random clinical trials are still needed to confirm such findings (Elfiky, 2020b).

Overall, several studies have demonstrated the effectiveness of repurposed drugs as therapeutic agents for COVID-19. Drug combinations are highly recommended instead of monotherapy to achieve effective elimination of SARS-CoV-2. The pharmacokinetics parameters of drugs, such as half-life, volume of distribution, clearance, and bioavailability, need to be considered for prescription of repurposed drug due to variability in paediatric and geriatric populations, and patients with underlying diseases.

On a second note, drug interactions need to be properly evaluated too to avoid adverse effects to the patients. Factors such as glucose6-phosphate dehydrogenase deficiency and cardiac Q-T prolongation, or any side effects caused by the repurposed drugs, should all be well considered before designing any regimen to COVID-19 patients. The battle against COVID-19 has not yet ended, so the search for its cure or any treatment options should continue.

\section{Acknowledgements}

The authors extend their gratitude to reviewers for critical comments on the manuscript.

\section{References}

Baron, S. A., Devaux, C., Colson, P., Raoult, D., \& Rolain, J. M. (2020). Teicoplanin: An alternative drug for the treatment of 
coronavirus COVID-19. International Journal of Antimicrobial Agents, 55(4), 105944.

Che Mat, N. F., Edinur, H. A., Abdul Razab, M. K. A., \& Safuan, S. (2020). A single mass gathering resulted in massive transmission of COVID-19 infections in Malaysia with further international spread. Journal of Travel Medicine, 27(3), taaa059.

Chen, D., Xu, W., Lei, Z., Huang, Z., Liu, J., Gao, Z., \& Peng, L. (2020). Recurrence of positive SARS-CoV-2 RNA in COVID-19: A case report. International Journal of Infectious Diseases, 93, 297-299.

Del Rio, C., \& Malani, P. N. (2020). COVID-19 - New insights on a rapidly changing epidemic. The Journal of the American Medical Association, in press. https://doi. org/10.1001/jama.2020.3072

Elfiky, A. A. (2020a). Ribavirin, Remdesivir, Sofosbuvir, Galidesivir, and Tenofovir against SARS-CoV-2 RNA dependent RNA polymerase (RdRp): A molecular docking study. Life Sciences, 253, 117592.

Elfiky, A. A. (2020b). Anti-HCV, nucleotide inhibitors, repurposing against COVID-19. Life Sciences, 248, 117477.

Gao, J., Tian, Z., \& Yang, X. (2020). Breakthrough: Chloroquine phosphate has shown apparent efficacy in treatment of COVID-19 associated pneumonia in clinical studies. BioScience Trends, 14(1), 72-73.

Gautret, P., Lagier, J. -C., Parola, P., Hoang, V. T., Meddeb, L., Mailhe, M., Doudier, B., Courjon, J., Giordanengo, V., Vieira, V. E., Tissot Dupont, H., Honore, S., Colson, P., Chabriere, E., La Scola, B., Rolain, J. -M., Brouqui, P., \& Raoult, D. (2020). Hydroxychloroquine and azithromycin as a treatment of COVID-19: Results of an open-label non-randomized clinical trial. International Journal of Antimicrobial Agents, 56(1), 105949.
Holshue, M. L., DeBolt, C., Lindquist, S., Lofy, K. H., Wiesman, J., Bruce, H., Spitters, C., Ericson, K., Wilkerson, S., Tural, A., Diaz, G., Cohn, A., Fox, L., Patel, A., Gerber, S. I., Kim, L., Tong, S., Lu, X., Lindstrom, S., Pallansch, M. A., Weldon, W. C., Biggs, H. M., Uyeki, T. M., Pillai, S. K., \& Washington State 2019-nCoV Case Investigation Team. (2020). First case of 2019 Novel Coronavirus in the United States. New England Journal of Medicine, 382(10), 929-936.

Lim, J., Jeon, S., Shin, H. -Y., Kim, M. J., Seong, Y. M., Lee, W. J., Choe, K. W., Kang, Y. M., Lee, B., \& Park, S. -J. (2020). Case of the index patient who caused tertiary transmission of COVID-19 infection in Korea: The application of Lopinavir/Ritonavir for the treatment of COVID-19 infected pneumonia monitored by quantitative RT-PCR. Journal of Korean Medical Science, 35(6), e79.

Puthanakit, T. (2010). Pharmacokinetics and 48-week efficacy of low-dose Lopinavir/ Ritonavir in HIV-infected children authors' response. Journal of Antimicrobial Chemotherapy, 65(4), 809-810.

Stebbing, J., Phelan, A., Griffin, I., Tucker, C., Oechsle, O., Smith, D., \& Richardson, P. (2020). COVID-19: Combining antiviral and anti-inflammatory treatments. The Lancet Infectious Diseases, 20(4), 400-402.

Wang, M., Cao, R., Zhang, L., Yang, X., Liu, J., Xu, M., Shi, Z., Hu, Z., Zhong, W., \& Xiao, G. (2020). Remdesivir and Chloroquine effectively inhibit the recently emerged novel coronavirus (2019-nCoV) in vitro. Cell Research, 30(3), 269-271.

Wu, Z., \& McGoogan, J. M. (2020). Characteristics of and important lessons from the coronavirus disease 2019 (COVID-19) outbreak in China: Summary of a report of 72314 cases from the Chinese Center for Disease Control and Prevention. The Journal of the American 
Medical Association, in press. https://doi. Yao, X., Ye, F., Zhang, M., Cui, C., Huang, B., org/10.1001/jama.2020.2648

Niu, P., Liu, X., Zhao L., Dong, E., Song, C., Zhan, S., Lu, R., Li, H., Tan, W., \& Liu, D. (2020). In vitro antiviral activity and projection of optimized dosing design of Hydroxychloroquine for the treatment of severe acute respiratory syndrome coronavirus 2 (SARS-CoV-2). Clinical Infectious Diseases, 71(15), 732-739. syndrome. The Lancet Respiratory Medicine, 8(4), 420-422. 